\title{
ABSURDO, SENTIDO E POLÍTICA \\ NO TEATRO DE VÁCLAV HAVEL: \\ UMA LEITURA DE GARDEN PARTY E LEAVING
}

\section{Absurdity, sense and politics in the theatre of Václav Havel: a reading of Garden Party and Leaving}

\author{
Katia Mendonça* \\ Universidade Federal do Pará - UFPA
}

\begin{abstract}
Resumo: O teatro de Václav Havel foi concebido em meio à luta política, se nutrindo tanto de elementos filosóficos quanto políticos. Um dos temas centrais em seu pensamento político e em seu teatro é a questão da transcendência que, em um aparente paradoxo, se vincula ao tema do absurdo. Garden Party e Leaving, primeira e última peças dele, revelam isso. Embora sejam diversas as influências intelectuais que Havel sofreu, nos propomos neste artigo analisar o papel de Masaryk e Patocka na constituição da tensão entre o absurdo e o sentido.
\end{abstract}

Palavras chave: Václav Havel; transcendência; absurdo; Thomas G. Masaryk; Jan Patocka.

Abstract: Václav Havel's theater was conceived in the midst of political struggle, nurturing both philosophical and political elements. One of the central themes in his political thought and his theater is the question of transcendence which, in an apparent paradox, is linked to the theme of absurdity. Garden Party and Leaving, first and last pieces of him, reveal this. Despite the various intellectual influences that Havel suffered, we propose in this paper to analyze the role of Masaryk and Patocka in the constitution of the tension between absurdity and meaning.

Keywords: Václav Havel; transcendence; absurdity; Thomas G. Masaryk; Jan Patocka. 
Se a relação entre ética e política em Václav Havel se estrutura sobre os temas da transcendência e do sentido, a sua estética se estrutura sobre o absurdo. Aparentemente contraditórias essas dimensões na verdade se revelam complementares. $\mathrm{O}$ pensamento político de Havel se constrói sobre uma busca intelectual e espiritual do sentido da vida e da relação deste sentido com a presença do Ser, termo que intercambia com outros com Sentido, Transcendente, Absoluto e Deus. A este tema central estarão afetas não só as demais questões referentes ao político, mas também aquelas que se encontram em sua obra dramatúrgico-literária (CAREY,1992; FALK, 2003). Tais dimensões se interconectam, mesmo que a princípio isso não o pareça e indique um paradoxo entre a esperança da qual muitas vezes ele fala em termos da política e o seu teatro do absurdo. Deste modo, o nonsense, o humor e a ironia das situações apresentadas em suas peças traduzem a sua visada ética, sua percepção da relação com o outro e com o mundo, com a esfera privada e com a esfera pública, cujos fundamentos encontrar-se-ão literariamente na tradição tcheca oriunda de Kafka, na filosofia de Masaryk e de Patocka e no teatro de Jan Grossman. Todos eles, intelectuais profundamente marcados, também eles, pela questão ética em uma sociedade burocrática e tecnologicamente avançada e, ao mesmo tempo, que perdeu a experiência de fé. É sobre este terreno, tendo como foco a primeira e a última peça de Havel:
Garden Party e Leaving, que, nos limites deste artigo, buscamos identificar em primeiro lugar as raízes filosóficas do pensamento e da estética havelianos, com especial destaque a Patocka e a Masaryk. Em seguida abordaremos a visão haveliana de transcendência. Isto a fim de mostrar que a incompatibilidade estrutural entre a temática do absurdo e a busca de transcendência se revela aparente em Havel e que se resolve quando abordamos as origens filosóficas do seu pensamento.

\section{Fundamentos filosóficos da estética de Havel}

Teatro, ética e política estão intimamente ligados em Havel que pensa o político a partir dos nexos éticos construídos entre os indivíduos e as teias de poder sociais e estatais, logo, contra toda a tradição ocidental. Segundo ele, o indivíduo só pode fazer face ao anonimato das teias de poder que o reduziriam à mera engrenagem se tiver uma percepção da Transcendência que caracteriza sua condição existencial.

Realmente: uma vida relativamente suportável nesta terra só pode ser assegurada por uma humanidade voltada para "além" deste mundo, uma humanidade que - em cada um de seus "aqui" e "agora"- se relaciona com o infinito, com o absoluto e com a eternidade. Dedicar-se irrestritamente ao "aqui" e "agora", por mais suportável que seja, transforma irremediavelmente o "aqui" e o "agora" em desolação e esterilidade e acaba por colori-lo com sangue". (HAVEL, 1992, p. 384) 


\section{Absurdo, sentido e política no teatro de Václav Havel:

O teatro de Havel é a expressão estética de sua busca intelectual e espiritual pelo sentido da vida e sua relação com a Transcendência, tema ao qual estarão afetas não só as questões referentes sua obra dramatúrgico-literária, mas também aquelas concernentes a seu pensamento político (CAREY,1992; FALK, 2003). Não sendo um filósofo profissional, mas sim um artista e um livre pensador, Havel utiliza a palavra Transcendência se inspirando em várias fontes intelectuais em um pensamento sem rigor conceptual. $O$ universo cultural onde prospera tem como fonte filosófica o diagnóstico realizado no início de século XX por Husserl e por Tomás Garrigue Masaryk sobre a crise espiritual do homem moderno, questões que se acham presentes na visão de mundo centro-européia que vai de Weber a Jan Patocka, passando por Gerog Simmel, Robert Musil e Kafka, opondo o mundo da vida ao mundo matematizado, a responsabilidade pessoal à impessoalidade e à racionalidade instrumental crescentes. Mas, terão particular destaque como fontes filosóficas para Havel, Masaryk e Patocka, cujas ideias são incorporadas em sua crítica tanto ao momento histórico totalitário quanto pós-totalitário.

Masaryk se contrapôs tanto ao idealismo alemãode Kanteaoextremosubjetivismo de Hegel quanto ao ultra-objetivismo de Marx. Em ambos presentes estavam os perigos do coletivismo e do esmagamento do indivíduo (vide SCRUTON, 1988 e CAPEK, 1988). Para ele a crise espiritual do mundo moderno se radica na irreligiosidade que é fruto do subjetivismo e do ceticismo que o acompanha. Esse mau subjetivismo teria como expoente principal a filosofia de Kant que lançou o homem no titanismo típico da modernidade. É a partir dessa crítica que Masaryk desenvolverá o conceito de "vida na verdade"- o qual será utilizado posteriormente por Patocka e por Havel - para dar conta da crítica à "vida na mentira" (a existência humana vivida falsamente, de acordo com a moralidade imposta pelos sistemas sócio-políticos). Tal visão carrega consigo uma percepção de moralidade na esfera pública. Subjacente a essa visão, encontramos nele a crença na imortalidade da alma, o que, segundo Patocka (1988, p. 113) estaria na base de seu pensamento político. Masaryk se inscreve em uma religiosidade mui próxima do protestantismo e prega uma religião moderna, uma "religião da humanidade" que, distante de igrejas seja "moral, social, nacional e espiritual; que seja convicção e não fé" (PUTNA, 2010, p. 355). O impacto do pensamento de Masaryk acerca de uma ética necessariamente precedendo a política, tendo por fundo uma religiosidade sem religião, livre das estruturas eclesiásticas e orientada por um comportamento moral na ação pública, será imenso sobre toda uma geração de intelectuais, incluindo o então conhecido ativista intelectual Vaclav M.Havel, pai de Havel, que herdará de Masarik a noção de "valores espirituais, mas não religiosos" (PUTNA, 2010, p. 
360), a qual deixará profunda impressão no filho. Masaryk, como Havel pai e posteriormente, o filho, expressam o que Simmel (2005 e 2009) chamaria de religiosidade, ou seja, a experiência de uma percepção de transcendência na realidade imanente, de uma abertura e de uma predisposição para o sentimento religioso, algo diferente de religião que, como fenômeno cultural, envolvendo regras e rituais, nasce da religiosidade.

Outra decisiva influência sobre Havel será Jan Patocka, cuja filosofia política nasce no plano pré-político, a partir da discussão acerca do cuidado da alma elaborado pelo pensamento platônico (ver RODRIGUEZ, 2008). Esta será a sua principal influência sobre Havel, permitindo-lhe uma abordagem antimaquiavélica da política. Patocka torna inseparável a dimensão política da dimensão ontológica. Para ele esta última precede àquela e da mesma deriva a dimensão ética e suas distinções entre justiça e injustiça, bem e mal, etc. (LAIGNEL-LAVASTINE, 1998, p. 20). A vida e obra de Havel indicam que ele verdadeiramente incorpora em seu pensamento e ação importantes categorias do filósofo tcheco, tais como dissidência, sacrifício e transcendência. Isso, cremos, é muito mais do que usar Patocka, um herói e mártir da resistência tcheca ao totalitarismo, como uma evocação simbólica da dissidência e das raízes nacionais tchecas sobre uma consciência pública, como pensa Putna (2010, p. 361).
A partir do pensamento husserliano, Patocka, aborda o mundo da vida como aquele que diz respeito à capacidade do homem de se relacionar consigo mesmo, com o outro e com o mundo de modo não utilitário, de tal maneira que no horizonte dessa relação emerjam as questões do sentido, da verdade e da responsabilidade. É pelo movimento que o homem se relaciona com o mundo da vida, segundo Patocka (2005). Para ele há três movimentos "mutuamente exclusivos e simultâneos" (vide BRENNAN, 2017, p.88). No primeiro movimento temos o enraizamento ao mundo, o habitat, a morada, o chez soi, a descoberta da corporeidade e a dependência em relação ao conhecido, a comunidade, o acolhimento, a confiança e a reciprocidade. $O$ segundo movimento é o do auto-sustento e da autoprojeção, do prolongamento de si no mundo através do trabalho, da relação com o mundo funcional e utilitário. Sendo necessário, este movimento é, contudo, o mais perigoso, diz Patocka, pois sua absolutização conduz ao drama do totalitarismo.

Esses dois movimentos se caracterizam por estarem presos à atividade do homem no mundo, não sendo ainda portadores da dimensão ética que, segundo Patocka, só emerge no terceiro movimento o qual se dá em direção à transcendência. Este é o movimento da verdade, do avanço em direção ao outro, do sair de si mesmo. Mas, antes de tudo é o movimento do cuidar da alma, no qual tomamos consciência do 
mundo e de nossa responsabilidade em relação a nós e ao outro, assim como "transcendemos a aparência e tomamos consciência das possibilidades e da transcendência inerentes a cada momento" (BRENNAN, 2017, p 92).

É o movimento que diante da fragilidade e da efemeridade, diante do face-a-face com a morte e com sua inevitabilidade, transcende esta realidade se recusando à alienação e à fuga. Movimento que vai em direção ao próximo, se recusando a cair no vazio e no niilismo, revelando a disponibilidade ao sacrifício em relação ao outro e ao coletivo. Como Patocka ressalta, a vida política é "ao mesmo tempo um não enraizamento permanente, uma não-fundação" (PATOCKA, 1981, p.52; LAIGNEL LAVASTINE, 1998, p.49). Logo, é um movimento rumo à transcendência, uma forma de viver do homem que se alça para além de sua própria sobrevivência, que se eleva e ultrapassa o subjetivismo egoísta; um verdadeiro e autêntico modo de vida.

A ideia de transcendência em Patocka é herdeira da dupla e tensa fidelidade que marca a sua filosofia que, segundo Ricoeur (s/d), une a metafísica e a fenomenologia e se erige para "o mais alto" que é a polis democrática. Patocka, na verdade, substitui a religião pela retomada da filosofia de Platão e de seu cuidado da alma, ou seja, adotando uma religiosidade que busca o sentido da existência em uma concepção de transcendência que não seria um poder divino externo como presente na concepção medieval, mas sendo antes uma visão que reduz Deus à ética e esvazia a realidade transcendente na realidade imanente (LONG, 1998).

A concepção de Patocka acerca da transcendência sem dúvida imprimirá sua marca na religiosidade de Havel (vide PUTNA, 2010), porém, o próprio fato deste intercambiar a palavra Transcendência com Sentido, Ser, Deus ou o Absoluto, demonstra a busca por um sentido da vida diante do "grande afastamento de Deus que experimentamos nos tempos modernos e para o qual não há equivalente na história" (HAVEL, 1991b, p.15; HAVEL, 1990, p.10-11 e POPESCU, 2012). Embora isso, Havel está longe de ser um místico ou alguém orientado por alguma espécie de ocultismo, como afirma Zantovský, seu biógrafo e amigo:

Entre os muitos paradoxos em torno de Václav Havel houve o fato de que, embora não fosse um homem religioso, ele era um homem de fé. Às vezes, ele se aproximava de Deus ao identificar essa "memória misteriosa do Ser", que informou seu pensamento filosófico e que deu uma base moral à sua política, mas, no final ele sempre esquivou. Seu deus, se Deus fosse, era uma forma de ser que não podia ser nomeado, retratado ou identificado de outra forma. A "ordem de ser", onde "todos as nossas ações são indelevelmente registradas e onde, e somente onde, serão devidamente julgadas" é um conceito que permeia seus escritos, desde Cartas a Olga até o seu último livro de memórias(...). Mas, ao contrário 
de muitas pessoas que passam pela vida sem se perguntar, Havel pôde ver o mistério da existência em toda ação, impulso e dilema humanos. E o núcleo do mistério era moral. Ele não diria que isso era superstição, assim como ele não o atribuía à Providência, ao Ser Supremo ou ao superego. Como ele argumentou várias vezes, o mistério não seria menor se lhe fosse dado um nome ou uma explicação. Isso apenas o tornaria mais distante. (ŽANTOVSKÝ, 2014, p. 556).

\section{Em busca do sentido}

Havel, como Masarik, irá perceber a crise espiritual do homem moderno como estreitamente vinculada tanto à perda da fé em uma Transcendência quanto à perda do contato com a experiência humana soterrada pela tecnologia, pela burocratização e impessoalidade. Embora seu respeito por todas as tradições religiosas, sua concepção não se vincula a uma religião específica. Também como herança de Masaryk, Havel percebe a condição humana como portadora de uma dimensão ética indissociável da religiosidade, a qual é fonte da responsabilidade ética. $\mathrm{Na}$ ausência desta surge o mal que, para ele, encontra-se na Nulidade, na ausência de Sentido, em um homem que se revolta contra Deus, se afasta de um centro e é jogado na solidão do mundo. Como Masaryk e Patocka, Havel foge do niilismo destacando que "a nulidade, a face moderna do diabo, penetra na vida das pessoas" (HAVEL, 1992, p. 179). A nulidade é o sentimento decorrente da falta de percepção do sentido da vida o qual se faz oculto e que no mais das vezes se apresenta através de sinais naquilo que seria o "milagre do Ser". O sentido da vida, que se faz eterno e permanente no mar do fugaz, do incerto e do efêmero, será dado pela Transcendência, pelo Ser: "e, se não quisermos nos render a ele por completo - ou seja, desistir de nossa trajetória (e assim, de nós mesmos) - devemos sentir que "tudo tem uma finalidade", que tudo tem uma direção, que não irá simplesmente deteriorarse por si mesmo, que não está meramente involucrado em sua própria acidentalidade temporária" (HAVEL, 1992, p. 190). Deste modo o Sentido será a fonte da fé, pois "a assunção de um horizonte absoluto naturalmente não explica nada. Entretanto constitui nossa única fonte de esperança, nossa única razão para a fé enquanto um (conscientemente refletido) estado mental" (HAVEL, 1992, p. 233).

A Transcendência, no sentido de Patocka, é a fonte da ética para Havel. Tudo o mais, incluindo as relações de autoridade que sustentam o tecido político e social, deve ter aí sua origem. A presente crise de autoridade do mundo contemporâneo é, para ele, unicamente expressão da "crise de espiritualidade" do homem atual. Esta é, sem dúvida, uma visão, no mínimo, estranha ao pensamento político tradicional que assenta a relação de autoridade em uma legitimidade de ideias e de procedimentos. O que Havel traz de novo é a constatação de que sem a crença 
em uma autoridade supraterrestre o conteúdo de legitimidade das relações de dominação no mundo tende a se diluir e, por fim, a desaparecer. A crença na Transcendência abriga a exigência ética de uma revolução individual precedendo a revolução política já que a corrupção espiritual faz parte de uma crise espiritual que tem por fonte 0 afastamento do homem em relação ao Absoluto, e assim só pode ser resolvida a partir do indivíduo e da recuperação do sentido da vida, da percepção do horizonte absoluto.

A coerência interior deste mundo se
deve à premissa de que ele existe
só porque existe algo por trás de seu
horizonte, adiante e em cima dele,
que escapa a nossa compreensão e
manipulação, dotando, justamente por
isto, este mundo de um fundo sólido,
de ordem e medida.(...) Significa que
o mundo natural tem em sua essência
uma premissa do Absoluto que o cria
e limita, espiritualiza e dirige, sem
o que seria impensável, absurdo e
inútil e que devemos respeitar; todo
o intento de depreciar, subjugar e
até de substituí-lo por algo diferente
representa uma manifestação de
orgulho que o homem há de pagar
caro, como Don Juan e Fausto.
(HAVEL, 1991, p. 73)

Assim, na perspectiva haveliana o espaço público está interligado com a esfera privada. A ética pública vincula-se à ética privada, não em um esvaziamento desta como no totalitarismo, mas, como um reflexo da responsabilidade de cada cidadão em relação à pólis, responsabilidade essa ancorada na visão de transcendência como acima discutido. $\mathrm{Na}$ esfera pública residirão as "diabólicas tentações do poder": nas portas que se abrem, nas mordomias, nas benesses, no uso do carro oficial, nas moradias suntuosas, na criadagem, etc., pequenos detalhes que seduzem e que tornam o homem escravo do poder. Cativo de sua posição, este homem tem no poder político a oportunidade de confirmar sua existência e identidade, mas ao mesmo tempo padece do risco daquele poder confiscar, negar e alienar essa identidade. (HAVEL, 1991a). Esta posição filosófico-política terá, como veremos, implicações diretas na obra dramatúrgica de Havel.

\section{Corrupção política como corrupção espiritual: Garden \\ Party e Leaving}

O teatro de Havel, como o teatro de dissidência da então Tchecoslováquia, é marcado por um compromisso em relação à denúncia da pobreza espiritual do homem e crescente matematização de sua vida, para usar a expressão de Patocka. A obra teatral de Havel se inicia com Garden Party (Zahradni Slavnost) (1963) e tem como última peça Leaving $(2007)^{1}$. Entre as duas temos vária outras peças importantes tais como Memorandum (1965), The Increased Difficult of Concentration (1968) e Largo Desolato (1985). Em todas o tema

1 Leaving foi transformada em filme com roteiro e direção do próprio Havel, tendo sido laureado com o 19th Czech Lion 2011como Melhor Roteiro e Melhor Edição, sendo também nominado para o Moscow International Film Festival 2011. 
central será a vida vazia de personagens girando em torno do poder e das suas "tentações", para usar a expressão do próprio Havel. Tentações estas que se acham presentes seja diante dos que estão no exercício do mais alto como do menor e mais miserável dos cargos, qualquer que seja o ponto de uma dada estrutura hierárquica (de ordem intelectual, política ou burocrática). É interessante destacar que o teatro de Havel compõe, em certo sentido, como que um círculo que se inicia com a primeira peça com o personagem Hugo Pludek - o jovem que busca, esperta e ansiosamente, entrar no sistema de poder totalitário e se dedica à caça de ínfimos cargos - e se fecha com a última com Vilém Rieger, o chanceler, político democrata de renome, um personagem que deixa, com dificuldades, o poder e lamenta a sua saída do sistema. Trinta e quatro anos separam Garden Party de Leaving e, embora esta última, como declarou Havel, tenha sido concebida antes da Revolução de Veludo, de 1989, apenas se materializou como processo criativo em 2007.

Ambas peças foram finalizadas em momentos históricos distintos, a primeira sob o julgo do totalitarismo soviético e a última sob o regime democrático. Como o conjunto do teatro haveliano, elas abordam a fragilidade de personagens que preenchem suas vidas com o prazer que encontram no exercício do poder. Marcados pelos jogos de interesse, pela hipocrisia e pelo vazio existencial, são vassalos de suas fraquezas e cobiças.
Assim, o teatro de Havel mostra que o absurdo da "vida na mentira", expressão de Masaryck, como vimos antes - continua para além da queda dos regimes totalitários. Pludek é um personagem do período totalitário que renasce em um personagem do mundo democrático, Vilém Rieger. Ambos vivem apegados ao poder. Ambos são prisioneiros e esvaziados de sentido porque esvaziados de uma percepção de transcendência, ou seja, são personagens que não ultrapassam o movimento de autoprojeção, que não superam o prolongamento de si no mundo utilitário, para usar a categoria de Patocka. A prisão a esse movimento se vincula ao anonimato das estruturas racionalizadas e ao niilismo que se impõem como visão do mundo dominante na sociedade pós-moderna; frutos da profunda crise espiritual do homem contemporâneo, da qual emerge o "homem geométrico", o qual não vive entre as coisas como elas são, mas sim mergulhado em seu próprio processo subjetivo, sem pontes para a vida autêntica (vide Patocka, 1988, p. 113). É este homem geométrico que encontramos tanto em Pludek quanto em Rieger, o que faz do teatro de Havel uma obra que, longe de ser datada, retrata o drama que avança implacavelmente, também sobre as sociedades ditas democráticas; um problema existencial do ser humano cujos laços de sociabilidade cada vez mais se esgarçam, algo que Gabriel Marcel, dentro da tradição filosóficodramatúrgica existencialista, na qual se 


\section{Absurdo, sentido e política no teatro de Václav Havel:

inspira o teatro do absurdo, chamaria de "mundo quebrado" (MARCEL, 1956).

Sabe-se da importância do existencialismo e de autores como Camus, Sartre e Marcel para o teatro do absurdo que expressa que "o homem está fora da harmonia e que, sem crença metafisica, encontra-se a si mesmo em um universo sem sentido" (BECKSON \& GANZ, 1989, p. 281), ou como afirmaria lonesco, "cortado de suas raízes religiosas, metafísicas e transcendentais, o homem está perdido; todas as suas ações tornamse insensatas, absurdas, inúteis" (ABRAMS, 1999, p. 3). É esta também a percepção que Havel para quem o teatro do absurdo foi "o mais importante fenômeno da cultura do teatro do século $X X$ ", porque "mostra a humanidade que perdeu a certeza metafisica fundamental, a experiencia do absoluto, a relação com o eterno, a sensação de que há sentido" (HAVEL, 1991, p. 53).

O que Jan Grossman afirma acerca do tema central de Garden Party como sendo a "mecanização do homem" responsável por sua corrupção espiritual e política (GROSSMAN, 1967, p. 118), vale também para as demais peças de Havel. Seu fundo está na cegueira ética e espiritual em relação à Transcendência. Ora, a corrupção espiritual para Havel, tratando da situação da Tchecoslováquia totalitária, é resultante de um regime assentado na mentira e no medo. O poder exemplar nefasto da corrupção detectado por
Havel será desastroso para o corpo político: impotência, hipocrisia e "servidão do espírito, insensibilização do coração e vazio existencial" (HAVEL, 1989, 22) se tornam comportamentos comuns entre os cidadãos. Esse é o mundo de Pludek, mas será também, sob estruturas políticas diversas, o mundo de Rieger.

Ambas as peças revelam a visão de Havel para quem, como para Patocka e Masaryk, há uma tensão na teia de relações travadas entre o nível político e o pré-político. Em ambos as ações têm efeito exemplar e recíproco com consequências que envolvem tanto os que estão dentro como os que estão fora do poder ou à sua margem. O efeito exemplar do modo como se relacionam essas esferas com os negócios públicos não é um problema restrito aos regimes totalitários, mas dirá respeito também às democracias. A corrupção material é sempre precedida da corrupção espiritual. Em Hugo Pludek esse estado de degradação será o terreno propício para a construção de uma vida na mentira. Hugo quer a qualquer custo entrar no sistema. Para isso incorpora a aprende uma nova língua marcada pelo nonsense burocrático. Embora jovem, adota ele o perfil de seus pais, também eles oportunistas, hipócritas e fracos espiritualmente diante do poder.

O oportunista Hugo é um camaleão social que se amolda ao regime e ao poder vigente. Tal personalidade longe está de ser um atributo unicamente dos 
homens nos regimes totalitários. Pelo contrário, Havel enfatizou muitas vezes que a crise espiritual do totalitarismo soviético também poder-se-ia reproduzir nas chamadas democracias, como de fato ocorre e como Leaving o expressa. Para Havel é a corrupção espiritual que alimenta a corrupção política e tal situação somente poderia ser superada pela dissidência que antes de ser política é espiritual (outro tema fruto da influência de Patocka).

Vilém Rieger, por sua vez, ex-chanceler de uma república democrática, diferentemente de Hugo, está em situação politicamente distinta, demissionário do cargo pelo término de seu mandato, tendo que se desapegar dos objetos e das benesses que recebeu durante seu mandado. Leaving sofre a influência de Tchekov e seu Jardim das Cerejeiras temperado com uma pitada do Rei Lear, de Shakespeare, e de Samuel Beckett (HAVEL, 2011).

\section{Enquanto em Garden Party os} personagens, submissos ao regime, adotam a máscara imposta pelo Estado totalitário a fim de manterem seus pequenos e miseráveis cargos, gravitando em torno do chefe do cerimonial, em Leaving os personagens também se mascaram, vivendo a vida na mentira, desta feita em uma democracia, sob a égide de uma falsa liberdade, posto que, embora politicamente sejam supostamente livres, não o são espiritualmente. Se na primeira peça o personagem luta para entrar na estrutura de poder, em sua última peça Havel apresenta a resistência à saída do poder por vias normais por parte de um político em um país democrático. Vilém Rieger está preso às pequenas coisas que terá de deixar para trás: a residência oficial onde habitou, com seu belo pomar, os objetos que ganhou de mandatários estrangeiros e, por fim, as lembranças de sua intervenção no mundo, de suas ideias e discursos. Como em Garden Party, os demais personagens gravitam em torno do personagem central. Eles são suas filhas, sua mãe, sua companheira e por fim os outsiders ao seu núcleo familiar, mas que dão o tom da relação de Vilém Rieger com o mundo: Bea, a estudante ambiciosa e sedutora, e Klein, seu adversário político e sucessor.

Ambos personagens, Pludek e Rieger, vivem a vida na mentira e dela não buscam sair, pois a verdade também é fruto de uma busca interior: "se estamos em busca da verdade, entretanto, o melhor é que a procuremos dentro de nós mesmos e o destino do mundo nos lança dentro dela. Se você não se esforça aqui dificilmente irá encontrá-la em outro lugar". (HAVEL,1992, p. 231). É a liberdade interior que permite ao homem fugir das "diabólicas tentações do poder" e alcançar a liberdade existencial e política. Será nesse plano, antípoda a Pludek e a Rieger, que irá ocorrer a dissidência. Justamente em situações existenciais onde há a perda de confiança nas forças externas e em Havel isso ocorre seja pelo ato político, 
seja pelo ato intelectual. No seu teatro o protesto recebe o manto da ironia, do sarcasmo e do humor dos quais nunca se afastou. $O$ tom patético de personagens presos em formalismos e apegados às pequenas coisas que dão momentaneamente sentido às suas vidas, encontramos por exemplo em uma passagem onde Pludek se nega em assumir qualquer identidade dizendo: "Eu? Quem sou eu? Olhe eu não gosto de perguntas colocadas de maneira tão unilateral, realmente não! Você acha que é possível perguntar de maneira tão simplificadora?" (HAVEL, 2010 , p. 89). E se lança em um longo monólogo marcado pelo nonsense e pela manipulação dos ouvintes.

Rieger, por seu turno, resiste em sair da casa que habitava como chanceler, de deixar para trás os objetos que ganhou durante o exercício do mandato, nessa obscura, como diz o próprio Havel, relação entre o público e o privado. Ao mesmo tempo, o personagem carrega consigo permanentemente, diante de jornalistas, ex-assessores e de seu arquiinimigo Klein (vice-primeiro ministro e provável futuro chanceler) um discurso oficial assentado como o de Pludek, em clichês. Eis que, ao final, Klein, o novo ocupante do poder, lhe oferece um cargo de "assessor do assessor do assessor do assessor do assessor do assessor do novo chanceler" (HAVEL, 2008b, p. 75) o que ele, incontinenti, aceita com a justificativa de que irá "servir à pátria"... O texto, recheado de clichês, soa aparentemente como uma zombaria que Havel faz de si mesmo e através de seu alterego Rieger e da dificuldade em deixar o poder. Ora, os clichês são a marca distintiva de seu teatro onde o absurdo das situações da vida é plasticamente transmitido de forma sarcástica e onde, como diria Jan Grossman, "não é o homem que usa o clichê, mas é o clichê que usa o homem" (GROSSMAN, 1967, p. 119).

No teatro haveliano o absurdo de situações morais corruptas, sem esperança, sem sentido, opõe-se à dissidência que buscando a vida na verdade é um movimento fruto da esperança $^{2}$ que, paradoxalmente, surge em meio aos perseguidos ou excluídos do poder, naquilo que Patocka chamou de "solidariedade dos abalados", termo incorporado por Havel em sua luta. Esta comunidade de dissidentes seria capaz de abalar, de mexer com a consciência das pessoas acerca em relação à sua própria liberdade, mostrando-lhes quão escravas de contextos sociais e políticos maiores o são e como têm em si as possibilidades de romper com tal situação. Daí é que irá surgir a ideia haveliana sobre o "poder dos impotentes", daqueles que exercem a dissidência negando a "vida dentro da mentira e a afirmando a "vida dentro da verdade", enquanto revolta do indivíduo contra uma condição a ele imposta por uma sociedade e por um Estado corruptos. A dissidência é, assim, um

\footnotetext{
2 Sobre uma leitura pragmática e relativista do pensamento de Havel sobre a esperança, desfocada de seu contexto e, logo, contraditória, vide Rorty (1998). Vide também a crítica em Deneen (1999).
} 
ato eminentemente moral dentro de uma sociedade marcada pela "crise profunda de identidade humana causada pela vida dentro da mentira" (HAVEL, 1989, p. 94). É através da dissidência que ocorre a revolução existencial que deve preceder, segundo Havel, a revolução política.

Além de sê-lo no teatro, o problema da vida na mentira seria denunciado por Havel em vários de seus ensaios (MENDONÇA, 2015), os quais retomam sistematicamente a questão da transcendência necessária para fazer face ao absurdo de tal vida. Assim, nele a incompatibilidade entre transcendência e absurdo é apenas aparente:

Preciso mencionar mais uma vez a complementaridade do sentido e do sem-sentido: quanto mais profunda a experiência da ausência do sentido, portanto do absurdo, tanto mais energicamente se procura o sentido; sem uma luta viva com a experiência do absurdo nada haveria com que se orientar; sem a profunda nostalgia interior do sentido não haveria, inversamente, a ferida do sem sentido. (HAVEL, 1991b, p. 186)

EmHavelaconcepçãodetranscendência, mesmo esvaziada do sentido medieval e ancorada no imanente, é que confere significado à vida, se vinculando, em um aparente paradoxo, ao absurdo, pois "o perfil do verdadeiro sentido só pode ser divisado diante do absurdo (...) são apenas duas faces da mesma moeda. Porque sem a sempre viva e articulada experiência do absurdo, não haveria motivo para nos esforçarmos por algo que fizesse sentido" (HAVEL, 1991b, p. 109). O absurdo é assim, "a sensação de quem percebe o sentido como dimensão integral da existência e pode sentir o quanto a ausência dele é dolorosa" (HAVEL, 1992, p. 181). E o teatro segue sendo o meio privilegiado de alerta e de denúncia do drama da existência humana oscilando entre o sentido e o absurdo. O teatro de Havel busca "enfiar o nariz em sua própria miséria, na minha miséria, em nossa miséria comum, lembrando-lhe que chegou a hora de fazer algo... Face a face com uma destilação do mal, o homem pode reconhecer o que é bom" (HAVEL, 1990, p. 199).

Então, pergunta-se porque Havel, que descobre o poder da linguagem como presente na questão dos clichês do poder totalitário representado pela língua Ptydepe de Memorandum, oscila entre usar os termos Deus, Sentido, Transcendência ou Ser em sua narrativa?

A beleza da linguagem é que ela nunca pode capturar precisamente o que deseja. A linguagem é desconectada, dura, e por essa razão, mas não só por essa razão, nunca pode capturar completamente algo tão conectado como a realidade, a experiência ou nossas almas. (...) Como indivíduo, e como espécie, ele [o homem] simplesmente tenta capturar o mundo e a si mesmo, cada vez com mais precisão através de palavras, de imagens ou de ações, e quanto mais ele consegue, mais consciente é de que nunca pode capturar completamente o mundo ou 
ele mesmo, nem qualquer parte do mundo. Mas isso o leva a continuar tentando, repetidas vezes, e assim ele continua a definir-se cada vez mais exatamente. É o destino de Sísifo. Mas ele não pode ser ajudado: o homem carregará a verdade completa sobre si mesmo para a sepultura, embora alguém, no final, conheça a verdade depois de tudo: se não o Senhor Deus, então, ao menos, a grande lembrança do Ser. (HAVEL, 2008a, não paginado)

Assim, conhecendo os limites do ser humano e em uma permanente busca de sentido Havel coloca o espectador diante da tensão entre o absurdo e a transcendência, consciente da infinitude da linguagem para dar conta do inenarrável e do mistério.

Recebido em: 03/03/2017

Aceito em: 05/06/2017

\section{Referências Bibliográficas}

ABRAMS, M. H. A Glossary of Literary Terms/ Seventh Edition. Heinle \& Heinle, Boston, USA, 1999.

BECKSON, K. and GANZ, A. Literary Terms: A Dictionary. Harper \& Collins, USA, 1989.

BRENNAN, Daniel. A Magnificent Gift: Jan Patocka and Vaclav Havel on Dissident Sacrifice. Theory in Action. Volume: 10, Issue: 1, January 1, 2017.

CAPEK. M. 1988. Masarik'personalism. In Margine of Two Recent evaluations of his Thought. In: NOVÁK. J. On Masaryk:
Texts in English and German. Rodopi, Amsterdam, 1988.

CAREY, P. "Living in Less: Vaclav Havel's Drama." Cross Currents 42, no. 2 (1992), p. 200.

DENEEN.P. J. The Politics of Hope and Optimism: Rorty, Havel, and the Democratic Faith of John Dewey. Social Research, 66, 2 (Summer 1999): p.577.

FALK. B.J. The Dilemmas of Dissidence in East-Central Europe: Citizen Intellectuals and Philosopher Kings. Central European University Press, Budapest, 2003.

GROSSMANN. J. Preface to Havel. The Tulane Drama Review, Vol. 11, No. 3 (Spring, 1967), p. 117-120

HAVEL, V. Essais Politiques. CalmannLévy, Paris, 1989.

HAVEL, V. Disturbing the Peace: A Conversation with Karel Hvizd'ala. Vintage Books, New York ,1990.

HAVEL, V. II est permi d'espérer. Calmann-Levy, Paris, 1997.

HAVEL, V. La responsabilidad como destino. Fondo de Cultura Económica, México, 1991.

\section{HAVEL,V. On temptations of polítical} power. Disponível em: https://www. cs.utexas.edu/users/vl/notes/havel.html 1991a.

HAVEL,V. Entrevista à Distância. Siciliano, São Paulo, 1991b.

HAVEL, V. Cartas a Olga. Estação Liberdade, São Paulo, 1992.

HAVEL,V. Meditaciones Estivales. Galaxia Gutenberg, Barcelona, 1994.

HAVEL, V. The Need for Transcendence in the Postmodern World. Disponível 
em: http://www.worldtrans.org/whole/ havelspeech.html ,1994.

HAVEL,V.ASense of the Transcendent. http://www.crosscurrents.org/havel.htm, 1995.

HAVEL,V. II est permis d'esperer. Calmann Lévy, Paris, 1997.

HAVEL,V . Pour une politique postmoderne. Éditions de l'Aube, Paris, 1999.

HAVEL,V. Without inner freedom you can achieve nothing. Interview. Irrawaddy, Vol.9, No.9, December, 2001. Disponível em: <http://www2.irrawaddy.com/article. php?art_id=2478 >

HAVEL,V. To the Castle and Back. Vintage Books. Kindle Edition, New York, [Livro Eletrônico não paginado] 2008a.

HAVEL,V. Leaving. Faber and Faber, London, 2008b.

HAVEL,V. Václav Havel: poesia e teatro. Annablume, São Paulo, 2010.

LAIGNEL-LAVASTINE, A. Jan Patocka:

L'Esprit de La dissidence. Éditions Michalon, Paris, 1998.

LONG, E. T. Quest for Transcendence.

The Review of Metaphysics. 52.205 (Sept. 1998): p. 3.

MARCEL, G. EI Mundo Quebrado:

Pieza em Cuatro Actos. Ediciones Losange, Buenos Aires, 1956.

MENDONÇA. K. Ethics and Politics in Václav Havel's Thinking. Trends in Slavic Studies (2015), 259-270.

PATOCKA.J. Essais hérétiques: sur la philosophie de l'histoire.Verdier, Paris, 1981.

PATOCKA.J. Spiritual crisis of European Humanity in Husserl and Masaryk. In:
Novák. Josep. On Masaryk: Texts in English and German. Rodopi, Amsterdam, 1988.

PATOCKA.J. EI movimiento de la existencia humana. Ediciones Encuentro, Madrid, 2005.

POPESCU, D. Political Action in Václav Havel's Thought: The Responsibility of Resistance. Lexington Books, Kindle Edition, United Kingdom, 2012.

PUTNA, M. C. The Spirituality of Václav Havel in Its Czech and American Contexts: Between Unitarianism and New Age, T. G. Masaryk and Kampademia. East European Politics and Societies, Volume 24, Number 3, Summer, 353-378, Sage Publications, 2010.

RICOEUR.P.. Em torno do Político. Loyola, São Paulo, 1995.

RICOEUR.P. Patocka, Jan (1907-1977). http://www.universalis.fr/encyclopedie/ jan-patocka/

RODRIGUEZ, I.O. The Ethical Impulse in Patocka Phenomenology: Phenomenology, Ethics and Politics. Focus Pragensis VIII (2008) 25-56.

RORTY, R. Truth and Progress. Cambridge University Press, Cambridge, 1998.

SIMMEL. G. Religião: ensaios volume 1/2. Olho d'água, São Paulo, 2009. SIMMEL.G. El problema religioso. Prometeo Libros, Buenos Aires, 2005.

SCRUTON. R. Masaryk, Patocka and the care of the soul. In: Novák. Josep. On Masaryk: Texts in English and German. Rodopi, Amsterdam, 1988.

ŽANTOVSKÝ, M. Havel, a Life. Atlantic Books, Great Britain, 2014. 